\title{
Dexamethasone intravitreal implant in the treatment of diabetic macular edema
}

\author{
This article was published in the following Dove Press journal: \\ Clinical Ophthalmology \\ 16 July 2015 \\ Number of times this article has been viewed
}

\section{Pravin U Dugel ${ }^{1,2}$ \\ Francesco Bandello 3 \\ Anat Loewenstein ${ }^{4}$}

'Retinal Consultants of Arizona, Phoenix, AZ, ${ }^{2}$ Department of Ophthalmology, Keck School of Medicine, University of Southern California, Los Angeles, CA, USA ${ }^{3}$ Department of Ophthalmology, University Vita-Salute Scientific Institute San Raffaele, Milan, Italy; ${ }^{4}$ Department of Ophthalmology, Tel Aviv Medical Center and Sackler Faculty of Medicine, Tel Aviv University, Tel Aviv, Israel
Correspondence: Pravin U Dugel Retinal Consultants of Arizona, II 0 I East Missouri Avenue, PO Box 32530, Phoenix, AZ 850I4-2709, USA

$\mathrm{Tel}+\mathrm{I} 602222222 \mathrm{I}$

Fax +l 6026822740

Email pdugel@gmail.com
Abstract: Diabetic macular edema (DME) resembles a chronic, low-grade inflammatory reaction, and is characterized by blood-retinal barrier (BRB) breakdown and retinal capillary leakage. Corticosteroids are of therapeutic benefit because of their anti-inflammatory, antiangiogenic, and BRB-stabilizing properties. Delivery modes include periocular and intravitreal (via pars plana) injection. To offset the short intravitreal half-life of corticosteroid solutions ( $\sim 3$ hours) and the need for frequent intravitreal injections, sustained-release intravitreal corticosteroid implants have been developed. Dexamethasone intravitreal implant provides retinal drug delivery for $\leq 6$ months and recently has been approved for use in the treatment of DME. Pooled findings $(n=1,048)$ from two large-scale, randomized Phase III trials indicated that dexamethasone intravitreal implant $(0.35 \mathrm{mg}$ and $0.7 \mathrm{mg})$ administered at $\geq 6$-month intervals produced sustained improvements in best-corrected visual acuity (BCVA) and macular edema. Significantly more patients showed a $\geq 15$-letter gain in BCVA at 3 years with dexamethasone intravitreal implant $0.35 \mathrm{mg}$ and $0.7 \mathrm{mg}$ than with sham injection (18.4\% and $22.2 \% \mathrm{vs} 12.0 \%)$. Anatomical assessments showed rapid and sustained reductions in macular edema and slowing of retinopathy progression. Phase II study findings suggest that dexamethasone intravitreal implant is effective in focal, cystoid, and diffuse DME, in vitrectomized eyes, and in combination with laser therapy. Ocular complications of dexamethasone intravitreal implant in Phase III trials included cataract-related events (66.0\% in phakic patients), intraocular pressure elevation $\geq 25 \mathrm{mmHg}$ $(29.7 \%)$, conjunctival hemorrhage $(23.5 \%)$, vitreous hemorrhage (10.0\%), macular fibrosis $(8.3 \%)$, conjunctival hyperemia $(7.2 \%)$, eye pain $(6.1 \%)$, vitreous detachment $(5.8 \%)$, and dry eye $(5.8 \%)$; injection-related complications (eg, retinal tear/detachment, vitreous loss, endophthalmitis) were infrequent $(<2 \%)$. Dexamethasone intravitreal implant offers a viable treatment option for DME, especially in cases that are persistent or treatment (anti-vascular endothelial growth factor/laser) refractory.

Keywords: corticosteroids, dexamethasone, intravitreal, implant, macular edema, diabetic retinopathy

\section{Introduction}

Diabetic retinopathy is a frequent microvascular complication of diabetes types 1 and 2 and represents the leading cause of blindness among adults of working age in the developed world. ${ }^{1}$ Diabetes-related central vision loss can arise either from microvascular occlusion (macular ischemia) or from microvascular leakage due to breakdown of the inner blood-retinal barrier (BRB), leading to thickening or swelling of the macula (macular edema). ${ }^{2,3}$ Diabetic macular edema (DME) affects an estimated 21 million individuals worldwide. ${ }^{4}$

Once diabetic retinopathy progresses to macular edema, treatment is indicated to slow the rate of vision loss and improve the long-term prognosis. For the past three decades, laser photocoagulation has been the mainstay of treatment for patients with 
DME; however, although effective in preserving vision, this form of therapy is of limited effect in restoring lost vision. ${ }^{5}$

In recent years, several alternative treatment options have emerged that offer the promise of long-term improvement in visual acuity, including intravitreal antivascular endothelial growth factor (anti-VEGF) agents and corticosteroids. ${ }^{5}$ Intravitreal anti-VEGF agents, either alone or as an adjunct to laser photocoagulation, have emerged as the preferred treatment for DME (particularly DME with foveal involvement) on account of their established efficacy, low incidence of complications, and relative ease of administration. Injectable intravitreal corticosteroids are effective agents for persistent or treatment-refractory DME, but their high rates of intraocular pressure (IOP) elevation and cataract consign their role to second-line therapy for most patients. In order to reduce the frequent dosing requirements of injectable intravitreal corticosteroid solutions and the associated risk of injection-related complications, sustained-release corticosteroid intravitreal implants have been developed.

Dexamethasone intravitreal implant $0.7 \mathrm{mg}\left(\mathrm{Ozurdex}^{\circledR}\right.$, Allergan, Inc., Irvine, CA, USA) is a biodegradable drug delivery system that has been approved for use in the treatment of macular edema secondary to retinal vein occlusion, noninfectious posterior uveitis, and more recently DME. This review evaluates the current evidence of the efficacy and safety of dexamethasone intravitreal implant in the treatment of DME.

\section{Role of inflammation in the pathogenesis of DME}

Early retinal microvascular changes in diabetes include thickening of the capillary basement membrane, loss of pericytes, vascular hyperpermeability, and capillary dilatation. Animal models have suggested that these changes can occur within weeks of diabetes onset. ${ }^{3,6,7}$ Hyperglycemia is the major driver of initial pathophysiology, with both the Diabetes Control and Complications Trial and the UK Prospective Diabetes Study firmly establishing an inverse correlation between proactive glycemic control and development of retinopathy. ${ }^{8,9}$ While the inciting events are still unclear, high concentrations of glucose are known to induce endothelial dysfunction, leading to BRB breakdown and retinal vascular leakage..$^{3,7,10,11}$ Disruption of tight junctions between vascular endothelial cells is a critical process in the development of DME. In the healthy retina, water and solute flux is actively controlled to maintain an effective osmotic gradient. ${ }^{11,12}$ Diabetes-induced retinal vascular inflammation critically modifies these processes, leading to BRB breakdown, extravasation of plasma proteins, and tissue edema. Formation of edema is often perpetuated by coexisting pathologies, such as dyslipidemia and hypertension, which has both pressure and inflammatory contributions.

DME displays features characteristic of a chronic, lowgrade, local inflammatory response. ${ }^{10}$ Vitreous fluid from patients with DME shows evidence of active inflammation, containing elevated levels of pro-inflammatory cytokines (tumor necrosis factor- $\alpha$ [TNF- $\alpha$ ], interleukin [IL] $1 \beta$ and IL-6, and high-mobility group box-1 protein [HMGB1]), chemokines (monocyte chemotactic protein 1 [MCP-1], RANTES [CCL5], IL-8, interferon gamma-induced protein 10 [CXCL10], and stromal cell-derived factor 1 [CXCL12]), angiogenic factors (VEGF and platelet-derived growth factor), and adhesion molecules (intercellular adhesion molecule 1 [ICAM-1] and vascular cell adhesion molecule 1) (Table 1). ${ }^{13-19}$ Levels of anti-inflammatory proteins, such as pigment epithelium-derived factor, are concurrently reduced. ${ }^{14}$ Activated microglia play an important role in early retinal inflammatory responses through the release of TNF- $\alpha$, while local inflammation directs the recruitment and irreversible attachment of circulating leukocytes to the retinal vascular endothelium (leukostasis), providing another important source of pro-inflammatory mediators. ${ }^{20-22}$ These elevations in ocular levels of inflammatory mediators do not correlate with plasma levels, indicating that the inflammation is locally driven, ${ }^{15,23}$ and this is further supported by evidence of enhanced pro-inflammatory gene transcription in DME-affected eyes. ${ }^{24}$

Intravascular and extravasated neutrophils perpetuate local inflammation by inciting microvascular damage and the release of stored mediators, and additionally have the potential to cause capillary occlusion..$^{20,22,25}$ Leukostasis is temporally and spatially linked to vascular leakage in murine models of diabetes. ${ }^{22}$ Neutrophils are also prominent producers of reactive oxygen species, which are thought to be important in regulating vascular permeability. ${ }^{6,13,26}$

Breakdown of the BRB and enhancement of vascular permeability in response to pro-inflammatory factors (most notably VEGF, TNF- $\alpha$, ICAM-1, MCP-1, and IL-1 $\beta)^{27,28}$ and reactive oxygen species ${ }^{29}$ are mediated through disassembly of tight junction proteins (occludins and cadherins) at intercellular tight junctions $\mathrm{s}^{30-32}$ and adherens junctions ${ }^{33}$ on vascular endothelial cells and retinal pigment epithelial cells. ${ }^{30,31}$ BRB breakdown can also be caused by cytokineinduced vascular cell death and by leukocyte-mediated vascular occlusion. ${ }^{22}$ 
Table I Key inflammatory mediators driving BRB breakdown in diabetic macular edema

\begin{tabular}{|c|c|}
\hline Mediator & Contribution to BRB breakdown \\
\hline Leukocytes & $\begin{array}{l}\text { Rich content of readily releasable mediators including cytokines, chemokines, superoxide, } \\
\text { and proteolytic enzymes that perpetuate inflammation, damage underlying EC, promote } \\
\text { BRB breakdown, and participate in tissue remodeling } \\
\text { Expression of Fas ligand directly encourages EC death (neutrophils) }\end{array}$ \\
\hline Growth factors & Phosphorylation of tight and adherens junctional molecules, leading to breakdown of BRB (VEGF) \\
\hline (VEGF, TGF $\beta$ ) & $\begin{array}{l}\text { Activation of ECs, expression of ICAM-I and VCAM-I, and leukostasis (VEGF) } \\
\text { Vascular remodeling via multiple pathways (TGF } \beta \text { in particular) }\end{array}$ \\
\hline $\begin{array}{l}\text { Oxidative stress } \\
\left(\mathrm{O}_{2}^{-}, \mathrm{H}_{2} \mathrm{O}_{2}, \mathrm{ONOO}^{-}\right)\end{array}$ & $\begin{array}{l}\text { Radicals cause cell damage and vasodilation, while having inherent signaling qualities, including } \\
\text { PKC activation } \\
\text { Increases the formation of AGE and lipid mediators } \\
\text { Activates production of pro-inflammatory mediators (superoxide/hydrogen peroxide) }\end{array}$ \\
\hline Cytokines (TNF- $\alpha$, IL-I $\beta$, & Stimulate the production and release of further pro-inflammatory mediators \\
\hline IL-6, HMGBI) & $\begin{array}{l}\text { Encourage reorganization of junctional proteins, leading to BRB breakdown (IL-6), sometimes } \\
\text { in conjunction with leukocyte recruitment (TNF, IL-I } \beta \text { ) } \\
\text { High local concentrations promote cell death, including ECs and pericytes (TNF, IL-I } \beta \text { ) }\end{array}$ \\
\hline Chemokines & Induce VEGF expression (SDF-I) \\
\hline (MCP-I, IL-8, SDF-I) & $\begin{array}{l}\text { Direct recruitment of cellular mediators toward the retina, from both the blood and within } \\
\text { the tissue (MCP-I, IL-8, SDF-I) } \\
\text { Can also directly induce EC junctional reorganization and BRB breakdown (IL-8) }\end{array}$ \\
\hline $\begin{array}{l}\text { Adhesion molecules (ICAM-I, } \\
\text { VCAM-I, P-selectin) }\end{array}$ & Allow attachment of blood leukocytes to ECs, initiating leukostasis and diapedesis \\
\hline AGE & Act on RAGE receptors to initiate mediator production \\
\hline Protein kinases (PKC) & $\begin{array}{l}\text { Phosphorylate junctional molecules to induce BRB breakdown (PKC) } \\
\text { Induce production/release of many other mediators (PKC) }\end{array}$ \\
\hline Lipid mediators and eicosanoids & Chemotactic for leukocytes $\left(\mathrm{LTB}_{4}\right)$ \\
\hline$\left(\mathrm{LTB}_{4}, \mathrm{PGE}_{1}, \mathrm{PGE}_{2}, \mathrm{PLA} 2\right)$ & $\begin{array}{l}\left.\text { Promote reorganization of EC junctional proteins, leading to BRB breakdown ( } \mathrm{LTB}_{4}, \mathrm{PGE}_{1}\right) \\
\text { Induce vasodilation }\left(\mathrm{PGE}_{2}\right) \\
\text { Promote retinal VEGF, ICAM-I, and TNF- } \alpha \text { expression (PLA2) }\end{array}$ \\
\hline MMP (MMP9) & $\begin{array}{l}\text { Digests basement membrane, releasing mediators and also weakening vascular support } \\
\text { Proteolytically activate chemokines } \\
\text { May aid the diapedesis of leukocytes but damage pericyte layer }\end{array}$ \\
\hline $\begin{array}{l}\text { Hypoxia (low } \mathrm{pO}_{2} \text { and high } \\
\text { metabolite levels) }\end{array}$ & $\begin{array}{l}\text { Induces production of pro-inflammatory mediators and initiates angiogenesis, both of which } \\
\text { encourage BRB breakdown }\end{array}$ \\
\hline
\end{tabular}

Abbreviations: AGE, advanced glycation end-products; BRB, blood-retinal barrier; EC, endothelial cell; HMGBI, high-mobility group box-I protein; ICAM-I, intercellular adhesion molecule I; IL, interleukin; LTB, leukotriene $B_{4}$; MCP-I, monocyte chemoattractant protein I; MMP, metalloproteinase; PGE, prostaglandin E; PKC, protein kinase C; PLA2, phospholipase A2; $\mathrm{PO}_{2}$, partial pressure of oxygen; RAGE, receptor for AGE; SDF-I, stromal cell-derived factor I; TGF $\beta$, transforming growth factor-beta; TNF, tumor necrosis factor; VCAM-I, vascular cell adhesion molecule I; VEGF, vascular endothelial growth factor.

Although a number of anti-inflammatory therapies significantly inhibit the development of DME, inhibition of specific mediators has been largely unsuccessful. ${ }^{13,23}$ This is likely because of the redundant nature of inflammation and suggests that a broader dampening of the immune response might offer the best means of restoring and protecting vision.

\section{Mechanism of action of intraocular corticosteroids in DME}

The ocular corticosteroids dexamethasone, triamcinolone acetonide, and fluocinolone acetonide are potent and selective agonists at the glucocorticoid receptor, of which multiple isoforms are expressed in ocular tissues. ${ }^{34}$ The resulting steroidreceptor complex translocates from the cell cytoplasm to the nucleus, where it brings about induction/repression of gene transcription, mRNA, and protein synthesis. ${ }^{35,36}$ In addition to these nuclear events, the steroid-receptor complex can trigger signal transduction events within the cytosol, ${ }^{35}$ such as the release of annexin- $1,{ }^{37}$ a modulator of leukocyte trafficking. ${ }^{38}$ In contrast to the nuclear actions of glucocorticoids, these "non-genomic" effects are rapid, since they are not mediated through mRNA/protein synthesis.

In DME, corticosteroids stabilize the existing retinal vasculature and are antiangiogenic, directly suppressing the production of paracrine angiogenic factors, including VEGF, and reducing the formation of new blood vessels. ${ }^{12,39}$ Through repression of key pro-inflammatory transcription factors, such as nuclear factor-kappa B (NFKB) and activator protein 1, the pro-inflammatory feedback loop established in macular edema is disrupted. ${ }^{13,23}$ Corticosteroids inhibit phospholipase $\mathrm{A} 2,{ }^{12}$ which is upregulated in the retinal microvasculature of the streptozotocin-induced diabetic rat ${ }^{40,41}$ and is implicated 
in retinal VEGF, ICAM-1, and TNF- $\alpha$ expression and retinal edema formation. ${ }^{41,42}$ Corticosteroids also induce expression of several anti-inflammatory proteins, including IL-10, adenosine, and $\mathrm{I} \kappa \mathrm{B} \alpha$, the natural inhibitor of $\mathrm{NF} \kappa \mathrm{B},{ }^{35}$ actively dampening the reaction. Intravitreal dexamethasone has been shown to reduce retinal leukostasis and vascular endothelial ICAM-1 expression in the diabetic rat model. ${ }^{43}$

At the BRB, corticosteroids act to maintain tight junction integrity by promoting tight junction protein expression and translocation to the endothelial/epithelial cell border, ${ }^{28}$ and by protecting against oxidative stress-induced disruption of tight junction proteins in retinal pigment epithelial cells. ${ }^{44}$ In addition to reducing retinal vascular permeability, corticosteroids also promote retinal fluid clearance through their effects on transcellular aquaporin-4 (AQP4) and potassium channels, the two main channels controlling retinal fluid movement on retinal Müller cells. ${ }^{45,46}$

The commonly used ocular corticosteroids, dexamethasone, triamcinolone acetonide, and fluocinolone acetonide, differ in their glucocorticoid receptor-binding affinity (dexamethasone $>$ triamcinolone acetonide $>$ fluocinolone acetonide) and lipophilicity (triamcinolone acetonide $>$ fluocinolone acetonide $>$ dexamethasone), ${ }^{34}$ which could potentially translate into clinically important differences in ocular activity.

\section{Barriers to intraocular delivery of corticosteroids}

The principal challenge in pharmacotherapy of retinal disease is how to achieve effective and sustained intraretinal drug concentrations while minimizing unwanted drug effects on other ocular structures. Ocular penetration of systemically administered drugs (particularly large and/or hydrophilic molecules) is restricted by the BRB, which comprises the tight junctions of the retinal vascular endothelium (inner $\mathrm{BRB}$ ) and the retinal pigment epithelium (outer BRB). For those drugs that do cross the BRB (small lipophilic molecules), the diluting effect of blood volume requires the use of large systemic doses, with the attendant risk of systemic adverse effects, while the rapid flow rate in the choroidal and retinal circulation limits drug exposure time.

The topically applied drug has to diffuse through multiple ocular tissues to reach the posterior segment of the eye. ${ }^{47}$ Ocular surface tear mechanisms are a major factor limiting initial drug exposure, while any drug that does manage to penetrate the corneal/conjunctival epithelia and sclera is liable to be removed by subconjunctival-episcleral blood and lymph flow, the choroidal circulation, and the transcellular xenobiotic efflux transporters of the retinal pigment epithelium. ${ }^{48}$ Consequently, topically administered ocular drugs show extremely low intravitreal bioavailability, typically of the order of $<0.001 \%{ }^{49}$

Likewise, periocular administration using the transscleral absorption pathway (subconjunctival, sub-Tenon's, or retrobulbar injection) encounters multiple anatomic barriers (episclera, sclera, choroid, Bruch's membrane, and retinal pigment epithelium) to drug delivery to the posterior eye. Moreover, trans-scleral clearance mechanisms (subconjunctival/episcleral lymphatics and blood flow, and choroidal blood flow) and outward-directed clearance flow from the vitreous humor (the posterior transretinal elimination pathway) further restrict drug penetration into target tissues of the posterior segment. ${ }^{50}$ Collectively, these factors result in low intravitreal bioavailability (typically $0.01 \%-0.1 \%$ ) for drugs administered via the periocular route. ${ }^{48}$

Intravitreal drug injection through the pars plana has the advantage of bypassing the BRB and achieving maximal intravitreal bioavailability. ${ }^{48}$ However, as a directly invasive technique, intravitreal injection carries risk of procedurerelated complications (notably IOP elevation, endophthalmitis, and retinal hemorrhage, tear, or detachment). Rates of endophthalmitis and retinal detachment are estimated at $0.2 \%$ and $0.05 \%$, respectively, per intravitreal injection. ${ }^{51}$ Moreover, the duration of action of intravitreally administered drugs is limited by the presence of drug clearance mechanisms, namely the posterior transretinal and anterior aqueous humor elimination pathways and the efflux transporters on the retinal pigment epithelium. ${ }^{48}$ For the commonly used ocular corticosteroids (dexamethasone, triamcinolone acetonide, and fluocinolone acetonide), the intravitreal halflife of the solubilized drug fraction is $2-3$ hours in monkey and rabbit eyes. ${ }^{34,52}$ Accordingly, for treatment of retinal disorders, frequent intravitreal injections of soluble corticosteroids would be required, placing considerable treatment burden on the patient, and also increasing the likelihood of procedure-related complications.

In order to prolong drug retention in the vitreous humor, several sustained-release systems have been developed, including injectable drug suspensions and biodegradable and non-biodegradable intravitreal implants. Biodegradable nanocarrier systems (liposomes, nanoparticles, nanocrystals, and nanoemulsions) are currently under development, and may have future application in the treatment of posterior eye disease. ${ }^{53}$ In addition to Ozurdex ${ }^{\circledR}$ (Allergan, Inc.; dexamethasone biodegradable implant), other sustained-release corticosteroid systems that are used intravitreally include 
Kenalog ${ }^{\circledR}$ (Bristol-Myers Squibb, Princeton, NJ, USA; triamcinolone acetonide suspension), Trivaris $^{\circledR}$ (Allergan, Inc.; triamcinolone acetonide suspension), Triesence ${ }^{\circledR}$ (Alcon, Fort Worth, TX, USA; triamcinolone acetonide suspension), Retisert $^{\circledR}$ (Bausch \& Lomb Inc., Rochester, NY, USA; fluocinolone acetonide non-biodegradable implant), and Iluvien ${ }^{\circledR}$ (Alimera Sciences, Inc., Alpharetta, GA, USA; fluocinolone acetonide non-biodegradable implant). Of these sustainedrelease corticosteroid systems, Ozurdex ${ }^{\circledR}$ and Iluvien ${ }^{\circledR}$ are currently approved for treatment of DME (Table 2). Factors that can influence drug release include the physicochemical characteristics of the implant (eg, drug-polymer interactions), the solubility of the drug in the vitreous humor, and the proximity of the implant to the primary elimination pathway. ${ }^{54}$ Posterior vitreous implant placement optimizes drug delivery to the retina and reduces drug exposure in the lens and trabecular meshwork, which are tissues associated with adverse ocular effects of corticosteroids (subcapsular cataract formation and IOP elevation). ${ }^{34}$

\section{Dexamethasone intravitreal drug delivery system}

Dexamethasone intravitreal implant, containing micronized preservative-free dexamethasone $0.7 \mathrm{mg}$ in a biodegradable copolymer of polylactic-co-glycolic acid (which eventually breaks down into carbon dioxide and water), is designed to deliver drug to the retina over a period of up to 6 months after intravitreal injection. By avoiding the peak vitreous drug concentrations produced by intermittent bolus corticosteroid injections and the need for frequent repeat injections, the implant may potentially reduce the risk of unwanted steroidassociated ocular effects (cataract formation, IOP elevation, and glaucoma) and injection-related complications (lens injury, retinal detachment, and infectious endophthalmitis). The insertion procedure, which is performed in the office under local anesthesia, involves placement of the rod-shaped implant (6 $\mathrm{mm}$ in length and $0.46 \mathrm{~mm}$ in diameter) in the vitreous cavity via pars plana injection with a single-use applicator and 22-gauge needle. To avoid vitreal reflux through the scleral puncture, a tunneled injection technique is used to create an angled intrascleral injection tract. Despite the relatively large diameter of the injector needle, the level of pain associated with the insertion procedure is not appreciably different from that produced by intravitreal anti-VEGF treatment, as administered with a 28 - to 30 -gauge needle. ${ }^{55}$ Since the implant is biodegradable, subsequent implant(s) can be inserted without the need for surgical removal of the existing implant.

High-speed, real-time photography of the injection procedure reveals that the impact velocity of the dexamethasone

Table 2 Comparative efficacy and safety of dexamethasone and fluocinolone acetonide intravitreal implants in diabetic macular edema

\begin{tabular}{|c|c|c|}
\hline & Ozurdex $^{\circledR}$ & Iluvien $^{\circledR}$ \\
\hline Active drug & Dexamethasone & Fluocinolone acetonide \\
\hline Formulation & Biodegradable implant & Non-biodegradable implant \\
\hline Dose & $0.7 \mathrm{mg}$ & $0.19 \mathrm{mg}$ \\
\hline Duration of action (months) & $\leq 6$ & $24-36$ \\
\hline FDA approval for DME treatment & 2014 & 2014 \\
\hline Phase III clinical trial in DME & $\mathrm{MEAD}^{82}$ & FAME $^{92}$ \\
\hline \multirow[t]{2}{*}{ Trial design } & rand, db, mc, sham controlled ${ }^{a}$ & rand, $\mathrm{db}, \mathrm{mc}$, sham controlled $\mathrm{d}^{\mathrm{b}}$ \\
\hline & $\mathrm{N}=1,048$ & $\mathrm{~N}=956$ \\
\hline \multicolumn{3}{|l|}{ Efficacy (\% patients) } \\
\hline \multirow[t]{2}{*}{$\geq 15$-ETDRS-letter BCVA gain at 3 years } & $18.4^{c}$ & $28.7^{d}$ \\
\hline & $22.2^{\mathrm{e}}$ & $27.8^{f}$ \\
\hline \multicolumn{3}{|l|}{ Ocular safety (\% patients) } \\
\hline \multirow[t]{2}{*}{ Elevated IOP } & $34.1^{\mathrm{c}}$ & $37.1^{d}$ \\
\hline & $36.0^{\mathrm{e}}$ & $45.5^{f}$ \\
\hline \multirow{2}{*}{ Cataract-related adverse events ${ }^{g}$} & 64. $1^{\mathrm{c}}$ & $81.7^{d}$ \\
\hline & $67.9^{\mathrm{e}}$ & $88.7^{f}$ \\
\hline \multirow[t]{2}{*}{ Incisional glaucoma surgery } & $0.3^{c}$ & $4.8^{d}$ \\
\hline & $0.6^{\mathrm{e}}$ & $8.1^{f}$ \\
\hline
\end{tabular}

Notes: aRescue laser not permitted; repeat treatment permitted at $\geq 6$-month intervals. ${ }^{b}$ Rescue laser permitted after 6 weeks; repeat treatment permitted at $\geq 12$-month intervals. 'Dexamethasone intravitreal implant $0.35 \mathrm{mg}$. ${ }^{\mathrm{d}}$ Fluocinolone acetonide low-dose intravitreal implant $(0.2 \mu \mathrm{g} / \mathrm{day})$. ${ }^{\mathrm{e}} \mathrm{Dexamethasone}$ intravitreal implant $0.7 \mathrm{mg}$.

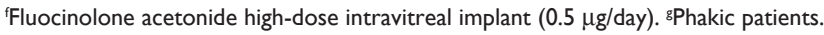

Abbreviations: BCVA, best-corrected visual acuity; db, double-blind; DME, diabetic macular edema; ETDRS, Early Treatment Diabetic Retinopathy Study; FDA, US Food and Drug Administration; IOP, intraocular pressure; mc, multicenter; rand, randomized; FAME, Fluocinolone Acetonide for Macular Edema. 
intravitreal implant, delivered using the applicator, is insufficient to cause retinal damage. ${ }^{56}$ Reported complications associated with the injection procedure include isolated cases of accidental lens injection ${ }^{57-59}$ and splitting or fracture of the implant either during or immediately after intravitreal injection. ${ }^{60-63}$ Inadvertent lens injection is an extremely rare event, but if it occurs, it can be managed successfully with prompt surgical extraction of the lens to avoid possible IOP elevation, and implantation of an intraocular lens. ${ }^{57-59}$ Implant fracture can result from misalignment of the implant within the applicator. ${ }^{61}$ Although the fragmented implant does not appear to cause more intraocular complications than the intact implant, monitoring for unexpected complications is recommended in such cases. ${ }^{60}$

Complications that have been reported with the implant in situ include isolated cases of migration into the anterior chamber, ${ }^{64-69}$ potentially leading to development of corneal edema. ${ }^{65,66}$ Aphakia and pseudophakia in association with imperfect zonular/posterior capsular integrity are risk factors for anterior chamber migration. ${ }^{65,69}$ Accordingly, use of dexamethasone intravitreal implant should be avoided in eyes with aphakia, an anterior chamber intraocular lens, or rupture of the posterior lens capsule.

\section{Pharmacokinetic profile of dexamethasone intravitreal implant} Pharmacokinetic studies in nonhuman primate (monkey) and rabbit eyes indicate that intraocular dexamethasone concentrations peak at 2-6 weeks after injection of the dexamethasone intravitreal implant, and that higher levels are achieved in the retina than in the vitreous. ${ }^{70,71}$ In the monkey eye, dexamethasone intravitreal implant $0.7 \mathrm{mg}$ shows a biphasic release pattern, with vitreal and retinal dexamethasone concentrations displaying a high plateau (vitreous, $\sim 100-1,000 \mu \mathrm{g} / \mathrm{mL}$; retinal, $\sim 100-1,000 \mu \mathrm{g} / \mathrm{g}$ ) during the first 2 months after implant insertion, declining sharply during the third month, and leveling off at a considerably lower plateau (vitreous, $\sim 0.1-1 \mathrm{ng} / \mathrm{mL}$; retinal, $\sim 0.1-1 \mathrm{ng} / \mathrm{g}$ ) for the next 3-4 months, reaching nondetectable levels after 7-8 months. ${ }^{70}$ Assuming that the steady-state concentrations of dexamethasone achieved in the monkey eye approximate to those in the human eye, these findings would suggest that dexamethasone intravitreal implant achieves higher and more steady vitreal drug concentrations during the initial release phase than subconjunctival, ${ }^{72}$ periocular, ${ }^{73}$ topical, ${ }^{74}$ or oral ${ }^{75}$ dexamethasone administration in human eyes.

Vitrectomy is known to accelerate the intraocular clearance of many drugs, including triamcinolone acetonide, ${ }^{76}$ and differences in drug disposition between nonvitrectomized and vitrectomized eyes may potentially influence the effectiveness of treatment. In contrast, a pharmacokinetic study in rabbit eyes indicated that vitreous and retinal dexamethasone concentration-vs-time profiles following injection of dexamethasone intravitreal implant $0.7 \mathrm{mg}$ were similar in nonvitrectomized and vitrectomized eyes. ${ }^{71}$

Systemic drug exposure from the dexamethasone intravitreal implant $(0.35 \mathrm{mg}$ or $0.7 \mathrm{mg})$ appears to be negligible in humans, and plasma dexamethasone concentrations are generally below the lower limit of quantification $(50 \mathrm{pg} / \mathrm{mL})$. Accordingly, the potential for systemic corticosteroid-related adverse effects with dexamethasone intravitreal implant is minimal.

\section{Efficacy of dexamethasone intravitreal implant in DME}

Several Phase II and Phase III studies have demonstrated the efficacy of dexamethasone intravitreal implant $(0.7 \mathrm{mg}$ or $0.35 \mathrm{mg}$ ) in improving visual and retinal anatomic outcomes in patients with DME (Table 3). A randomized, single-masked, 6-month, Phase II study involving incisional vitreous placement of the dexamethasone implant in patients with persistent DME $(n=171)$ provided evidence of a possible dose-response relationship, with more patients achieving a $\geq 10$-letter or $\geq 15$-letter gain in best-corrected visual acuity (BCVA) with dexamethasone implant $0.7 \mathrm{mg}$ than with dexamethasone implant $0.35 \mathrm{mg}$ at 2 months, 3 months, and 6 months; however, the differences between the active treatment groups were not statistically significant. ${ }^{77}$ Significant improvements in macular thickness and retinal capillary leakage were noted at 6 months in the dexamethasone implanttreated patients compared with nontreated controls; as with the visual acuity findings, these anatomic responses tended to be more pronounced with the $0.7 \mathrm{mg}$ than with the $0.35 \mathrm{mg}$ dose. In a subsequent analysis of data from this study, dexamethasone intravitreal implant was found to display similar efficacy in focal, cystoid, and diffuse DME. ${ }^{78}$

Evidence of accelerated clearance of corticosteroids from vitrectomized compared with nonvitrectomized eyes ${ }^{76,79}$ might suggest that the clinical benefits of dexamethasone intravitreal implant would be reduced by vitrectomy. The CHAMPLAIN study, a multicenter, open-label, noncomparative, 6-month, Phase II investigation of the efficacy and safety of dexamethasone intravitreal implant $0.7 \mathrm{mg}$ in patients with treatment-resistant DME and prior pars plana vitrectomy $(n=55)$ reported sustained improvements in visual and anatomic outcomes in this difficult-to-treat 


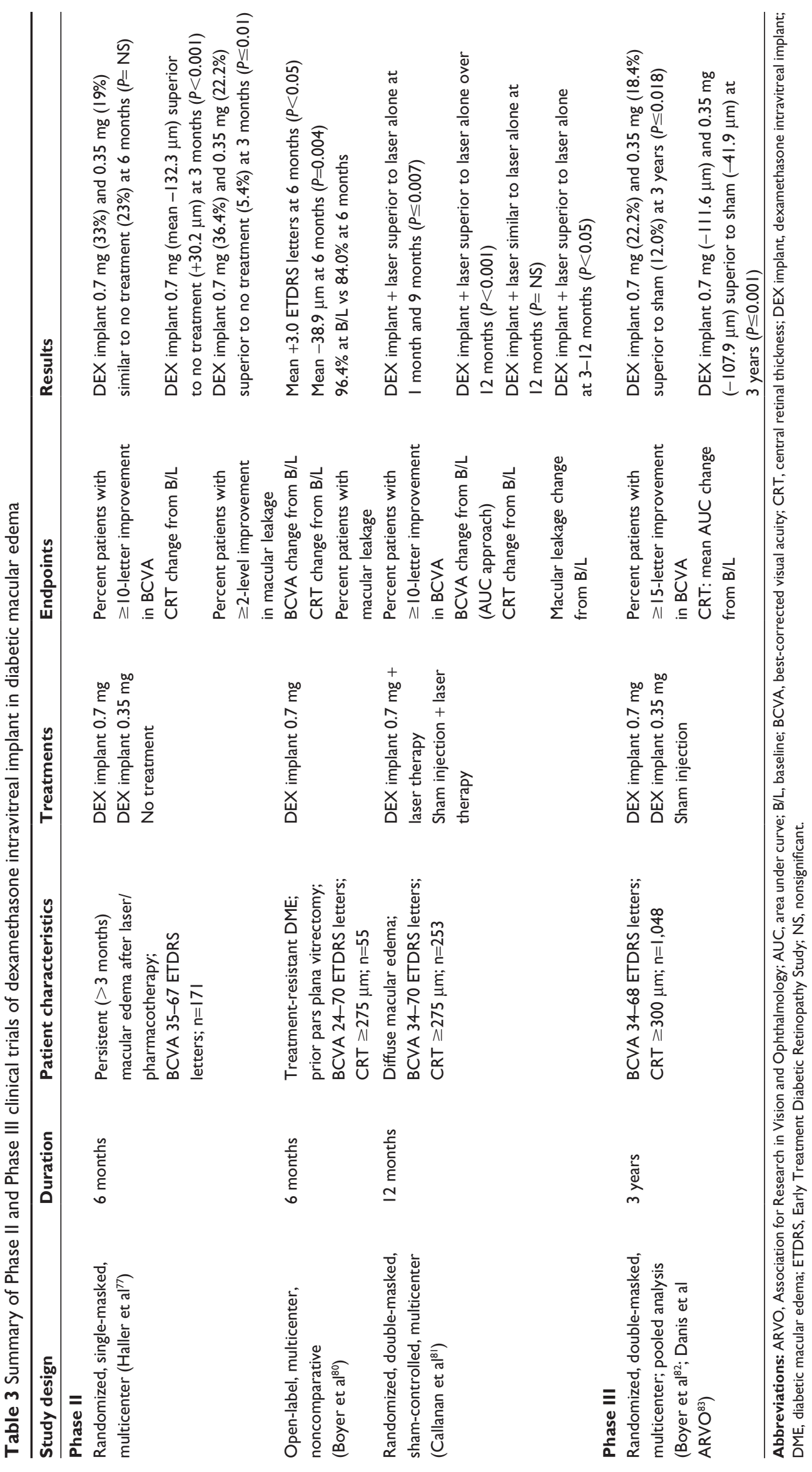


patient group. ${ }^{80}$ Improvements from baseline in BCVA and central subfield retinal thickness peaked at 2-3 months postinjection and persisted, albeit at a diminished level, until the end of the study. ${ }^{80}$

A randomized, double-masked, sham-controlled, 12-month, Phase II study of dexamethasone implant $0.7 \mathrm{mg}$ in combination with laser therapy in patients with diffuse DME $(n=253)$ found that dexamethasone implant plus laser therapy produced greater improvements in BCVA, macular thickness, and capillary leakage than laser therapy alone, although in most cases the treatment advantage was not sustained for the full 12 months. ${ }^{81}$ Patients received dexamethasone implant at baseline and laser therapy at month 1, and could receive up to three additional laser treatments and one additional dexamethasone implant treatment as needed. Significantly more patients showed $\mathrm{a} \geq 10$-letter gain in BCVA with dexamethasone implant $0.7 \mathrm{mg}$ plus laser therapy than with laser therapy alone at 9 months $(31.7 \%$ vs $17.3 \%)$ but not at 12 months $(27.8 \%$ vs $23.6 \%$ ). Analysis of the change from baseline in BCVA over the 12-month study period indicated significantly greater improvement with dexamethasone implant plus laser than with laser alone. Central subfield retinal thickness was reduced to a significantly greater extent in the dexamethasone implant plus laser group than in the laser-alone group during the first 4 months, while vascular leakage showed a significantly larger reduction in the dexamethasone implant plus laser group than in the laser-alone group over the full 12 months.

Two large, multicenter, randomized, Phase III clinical trials to evaluate the long-term safety and efficacy of dexamethasone implant have recently been completed in patients with DME. ${ }^{82}$ Patients with a BCVA of 34-68 letters (20/200-20/50 Snellen equivalent) and central subfield retinal thickness $\geq 300 \mu \mathrm{m}$ were randomized to treatment with dexamethasone implant $0.7 \mathrm{mg}$ or $0.35 \mathrm{mg}$, or sham procedure and followed for 3 years. As the trials were of identical design, the results were pooled for analysis (total of 1,048 patients). ${ }^{82}$ Dexamethasone implant $0.7 \mathrm{mg}$ and $0.35 \mathrm{mg}$, administered at $\geq 6$-month intervals over 3 years, provided robust long-term improvement in visual acuity and macular edema, with significantly more patients showing a $\geq 15$-letter gain in BCVA at the end of the study with dexamethasone implant $0.7 \mathrm{mg}$ and $0.35 \mathrm{mg}$ than with sham injection $(22.2 \%$ and $18.4 \%$ vs $12.0 \% ; P \leq 0.018)$. Although the changes in visual acuity were confounded by development and/or progression of cataract in a substantial proportion of phakic eyes after the first year, significant overall improvement in
BCVA over the 3-year treatment period was obtained with dexamethasone implant.

Anatomical assessments, using optical coherence tomography, fundus photography, and fluorescein angiography, indicated that dexamethasone implant $0.7 \mathrm{mg}$ and $0.35 \mathrm{mg}$ produced rapid and sustained reductions in measures of macular edema over the 3-year treatment period, and slowed retinopathy progression. ${ }^{83}$ On completion of 3 years of treatment with dexamethasone implant $0.7 \mathrm{mg}$ and $0.35 \mathrm{mg}$, significant reductions (vs sham procedure) were noted in central subfield retinal thickness (mean, $-111.6 \mu \mathrm{m}$ and $-107.9 \mu \mathrm{m}$ vs $-41.9 \mu \mathrm{m}$ ), macular volume (mean, $-1.06 \mathrm{~mm}^{3}$ and $-1.14 \mathrm{~mm}^{3} \mathrm{vs}-0.31 \mathrm{~mm}^{3}$ ), and area of central retinal thickening (mean, -2.75 and -2.93 vs -1.49 disk areas). Patients treated with dexamethasone implant $0.7 \mathrm{mg}$ and $0.35 \mathrm{mg}$ were significantly more likely to show an improvement in clinically significant macular edema after 3 years than sham-treated controls (20.4\% and $22.4 \%$ vs $12.4 \%$ ). In addition, treatment with dexamethasone implant $0.7 \mathrm{mg}$ slowed the progression of diabetic retinopathy, delaying by approximately 12 months the onset of two-step progression in Diabetic Retinopathy Disease Severity Score. ${ }^{84}$

Small-scale, short-term exploratory studies and retrospective case studies suggest that dexamethasone intravitreal implant $0.7 \mathrm{mg}$ is of potential benefit in persistent, treatment-refractory DME, including cystoid macular edema (Figures 1 and 2). A prospective study in 15 patients (16 eyes) with chronic DME nonresponsive to bevacizumab (as indicated by the absence of clinically significant reduction in CRT after at least three monthly bevacizumab injections) reported significant improvements in BCVA and central subfield retinal thickness for up to 3 months after insertion of dexamethasone intravitreal implant. ${ }^{85} \mathrm{~A}$ retrospective study assessing the effects of dexamethasone intravitreal implant $0.7 \mathrm{mg}$ in 33 patients (37 eyes) with prolonged, treatment-refractory cystoid macular edema of various etiologies reported significant improvements in BCVA (mean 2-3 Early Treatment Diabetic Retinopathy Study lines from baseline) and central macular thickness (46\% decrease) during approximately 6 months of follow-up in the subset of patients (14 eyes) with DME. ${ }^{86}$ In a retrospective review of medical records of 58 patients with chronic DME that was refractory to laser and intravitreal anti-VEGF and/or intravitreal steroid therapy, dexamethasone intravitreal implant produced significant improvement in BCVA and foveal thickness for up to 6 months post-insertion. ${ }^{87}$ Favorable results have also been reported with dexamethasone intravitreal implant in small cohorts of patients with persistent DME..$^{88,89}$ 

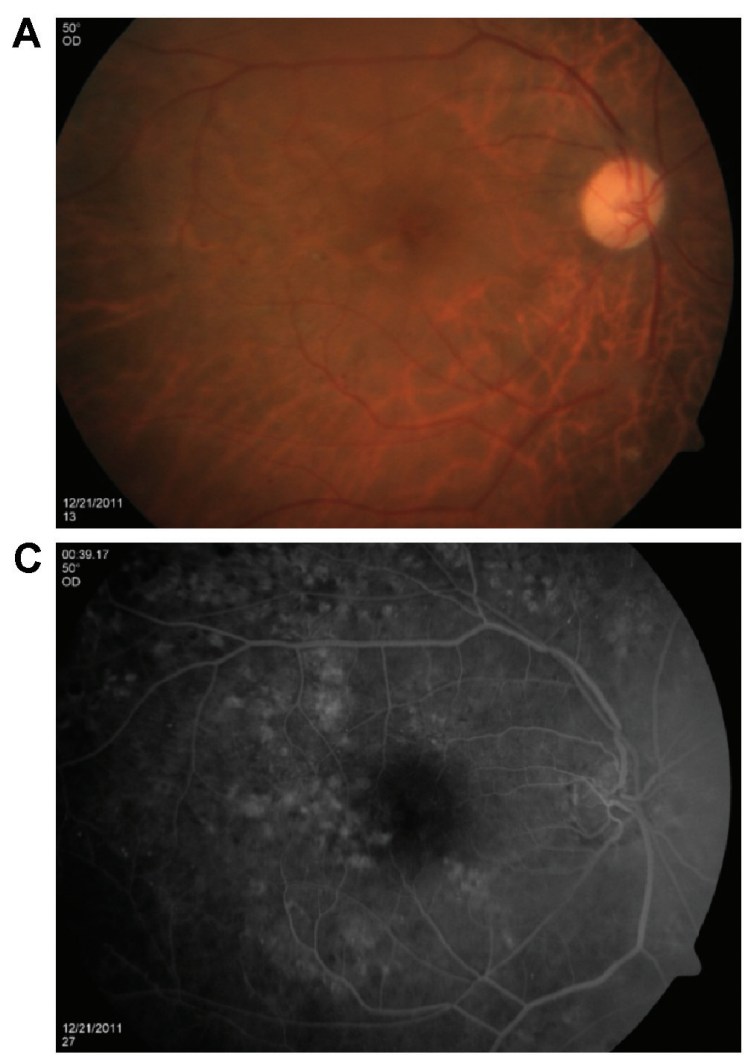

E

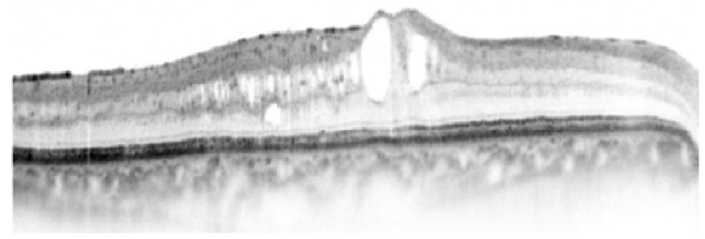

G

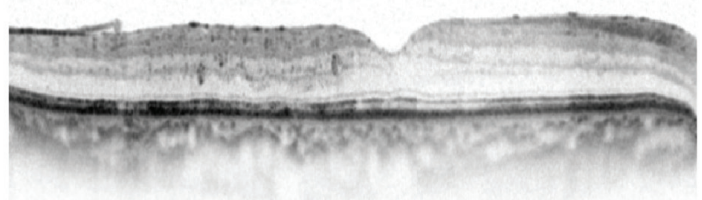

B

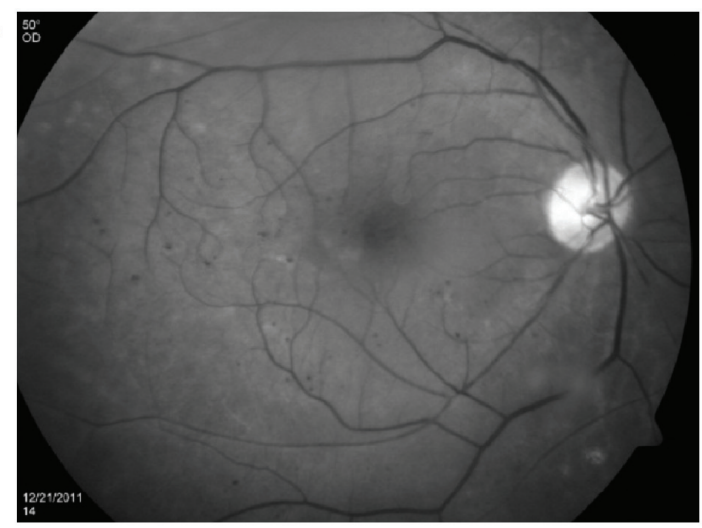

D

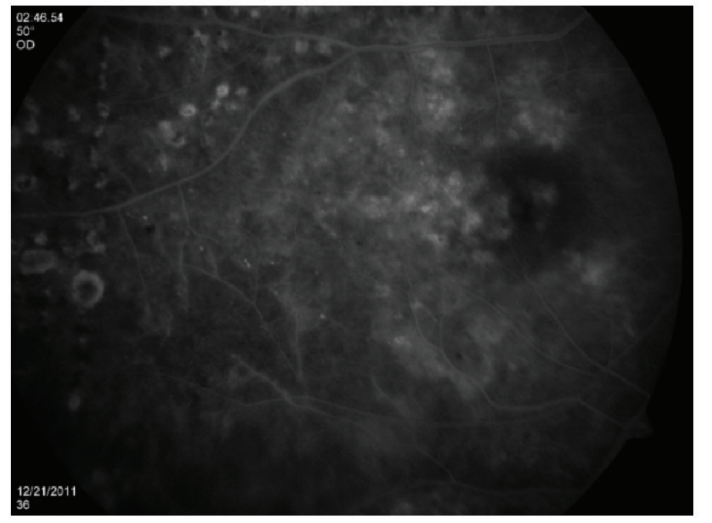

$\mathbf{F}$

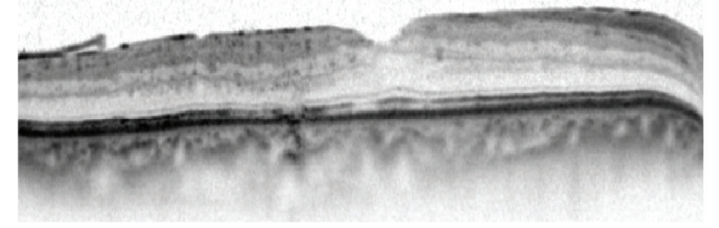

H

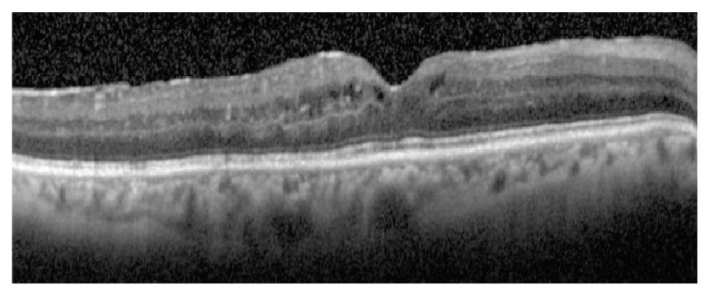

Figure I A 64-year-old male diagnosed with diabetic macular edema in the right eye.

Notes: Color and red-free fundus photographs of the RE indicate thickening of the fovea, as well as intraretinal small hemorrhages and microaneurysms (A and B). After ten monthly bevacizumab injections, optical coherence tomography indicates marked macular thickening, while fluorescein angiography fails to identify any treatable lesions (C and D). Intravitreal injection of dexamethasone implant reduces central macular thickness from a baseline (post-bevacizumab) level of 4 I $2 \mu \mathrm{m}$ (BCVA $6 / 12$ ) (E) to $286 \mu \mathrm{m}$ (BCVA 6/I0) at 6 weeks (F), $285 \mu \mathrm{m}$ (BCVA 6/I2) at I2 weeks (G), and $309 \mu \mathrm{m}$ (BCVA 6/I5) at I8 weeks postinjection (H). Images courtesy of Dr A Loewenstein.

Abbreviation: BCVA, best-corrected visual acuity.

\section{Tolerability of dexamethasone intravitreal implant}

Common complications of ocular corticosteroid therapy are IOP elevation and cataract formation/progression. In the Phase III registration studies of dexamethasone intravitreal implant $0.7 \mathrm{mg}$ and $0.35 \mathrm{mg}$ in the treatment of DME, ${ }^{82}$ $29.7 \%$ of patients treated with dexamethasone implant (compared with $4.3 \%$ of sham-treated patients) showed clinically significant IOP elevation (IOP $\geq 25 \mathrm{mmHg}$ ). In most cases, this was managed with ocular hypotensive medication or observation, and only seven patients $(1.0 \%)$ required glaucoma incisional surgery (three patients, $0.4 \%$ ) or IOP-lowering laser therapy (four patients, $0.6 \%$ ). The increase in IOP was generally transient, reaching a peak at approximately 6 weeks after each dexamethasone implant injection, with IOP returning to baseline levels within 


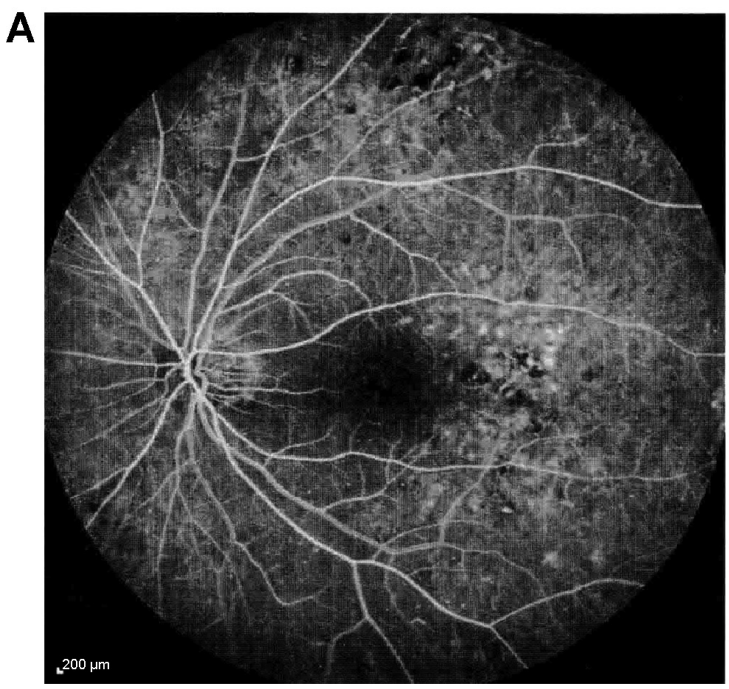

B

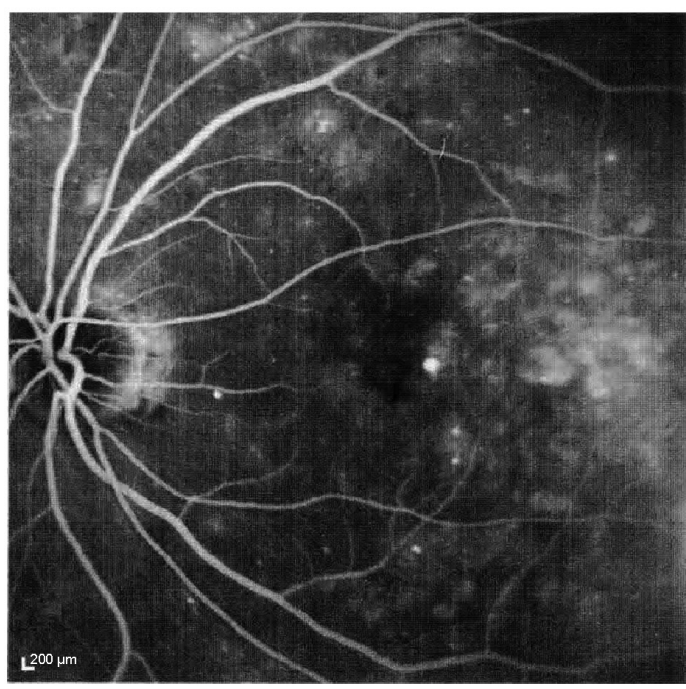

D

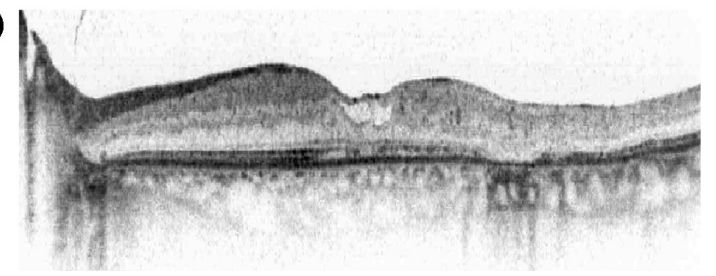

Figure 2 A 62-year-old patient with cystoid macular edema in the left eye previously treated with three monthly injections of intravitreal bevacizumab.

Notes: Early- and late-phase fluorescein angiograms indicate diffuse leakage temporal to the fovea, and distortion of the foveal avascular zone with some non-perfusion (A and B). Optical coherence tomography images indicate a decrease in central macular thickness from a baseline (post-bevacizumab) level of $475 \mu \mathrm{m}$ (C) to $235 \mu \mathrm{m}$ at 3 months after dexamethasone implant injection (D), with improvement in BCVA from 20/60 to 20/40 over this period. Images courtesy of Dr A Loewenstein.

Abbreviation: BCVA, best-corrected visual acuity.

6 months postinjection. The incidence and extent of IOP elevation after each dexamethasone implant injection did not change appreciably over the 3-year treatment period. Among phakic patients, $66.0 \%$ experienced a cataract-related adverse effect (cataract, cataract cortical, cataract nuclear, cataract subcapsular, or lenticular opacities) during treatment with dexamethasone implant (compared with 20.4\% of sham-treated patients), and $55.8 \%$ of dexamethasone implant-treated patients required cataract surgery during the study (compared with $7.2 \%$ of sham-treated patients). The incidence of cataract-related adverse effects increased during the second and third years of treatment with dexamethasone implant, and most cataract surgery procedures occurred during this period.

In addition to elevated IOP and cataract, the most frequent adverse events reported with dexamethasone intravitreal implant in the Phase III studies in DME included conjunctival hemorrhage (23.5\%), vitreous hemorrhage (10.0\%), macular fibrosis $(8.3 \%)$, conjunctival hyperemia $(7.2 \%)$, eye pain (6.1\%), vitreous detachment $(5.8 \%)$, and dry eye $(5.8 \%)^{82}$ (Table 4). Injection-related adverse effects, such as retinal tear, retinal detachment, vitreous loss, and endophthalmitis, occurred in $<2 \%$ of patients.

\section{Place of dexamethasone intravitreal implant in management of DME}

In comparison to the other sustained-release corticosteroid delivery systems, dexamethasone implant has the advantage

Table 4 Most frequently reported adverse events in Phase III studies of dexamethasone intravitreal implant in the treatment of diabetic macular edema

\begin{tabular}{|c|c|c|c|}
\hline \multirow[t]{2}{*}{ Adverse event } & \multicolumn{3}{|c|}{ Incidence (\% patients) } \\
\hline & $\begin{array}{l}\text { DEX implant } \\
0.35 \mathrm{mg}\end{array}$ & $\begin{array}{l}\text { DEX implant } \\
0.7 \mathrm{mg}\end{array}$ & $\begin{array}{l}\text { Sham } \\
\text { control }\end{array}$ \\
\hline Cataract related $^{a}$ & 64.1 & 67.9 & 20.4 \\
\hline IOP elevation ${ }^{\mathrm{b}}$ & 27.4 & 32.0 & 4.3 \\
\hline Conjunctival hemorrhage & 25.9 & 21.0 & 12.9 \\
\hline Vitreous hemorrhage & 13.1 & 6.9 & 7.1 \\
\hline Macular fibrosis & 10.8 & 5.8 & 2.9 \\
\hline Conjunctival hyperemia & 8.7 & 5.8 & 5.4 \\
\hline Vitreous detachment & 6.7 & 4.9 & 2.3 \\
\hline Retinal hemorrhage & 5.8 & 4.0 & 4.3 \\
\hline Dry eye & 5.5 & 6.1 & 2.6 \\
\hline Conjunctival edema & 5.0 & 4.3 & I.I \\
\hline Conjunctivitis & 4.4 & 5.5 & 2.3 \\
\hline
\end{tabular}

Notes: ${ }^{2} \mathrm{C} a t a r a c t$, cataract cortical, cataract subcapsular, cataract nuclear, or lenticular opacities. ${ }^{\text {llOP }} \geq 25 \mathrm{mmHg}$. Data from Boyer et al..$^{82}$

Abbreviations: DEX implant, dexamethasone intravitreal implant; IOP, intraocular pressure. 

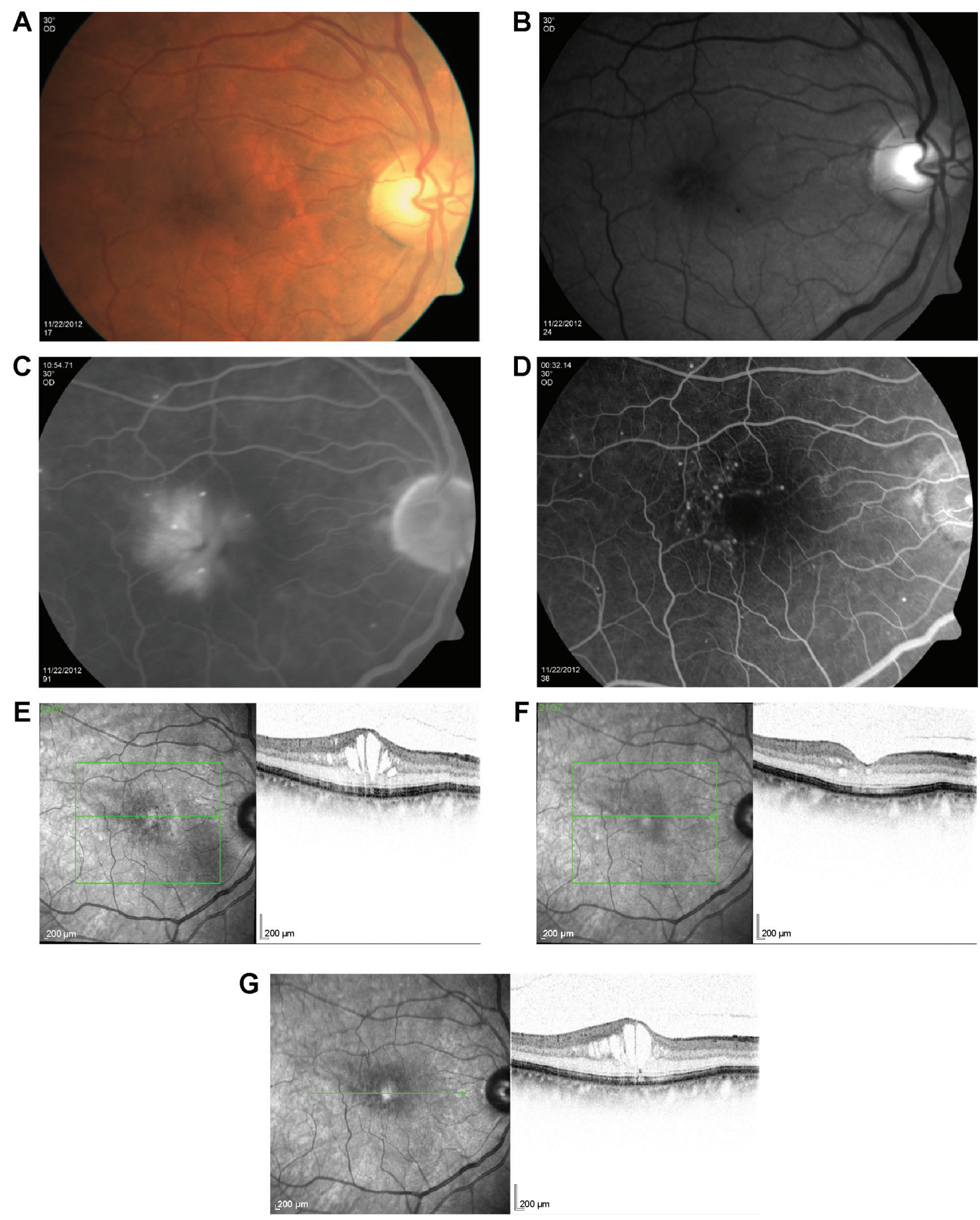

Figure 3 A 72-year-old patient with diabetic macular edema in the right eye previously treated with three monthly injections of intravitreal bevacizumab.

Notes: Color and red-free fundus photographs ( $\mathbf{A}$ and $\mathbf{B})$ and fluorescein angiograms (C and $\mathbf{D})$ of the right eye show multiple microaneurysms, as well as leakage primarily in the temporal fovea, with accumulation in a cystoid pattern. Optical coherence tomography images indicate a central macular thickness of $525 \mu \mathrm{m}$ on presentation (E), which transiently decreases to $269 \mu \mathrm{m}$ at I month after dexamethsone implant injection (F) before returning to pretreatment levels (534 $\mu \mathrm{m})$ at 3 months postinjection (G). Images courtesy of Dr A Loewenstein.

of ease of administration, and the implant injection can be performed in the outpatient setting, while the biodegradable polymer matrix allows re-treatment without the need for surgical removal of the existing implant. The major challenge with intravitreal corticosteroid implants is their high rate of intraocular complications, notably IOP elevation and cataract. Dexamethasone is less lipophilic than fluocinolone acetonide and triamcinolone acetonide and shows less sequestration in the lens and trabecular meshwork, ${ }^{90}$ and hence has potentially lower risk of causing IOP elevation and 
cataract; however, this has yet to be confirmed in head-tohead comparisons of dexamethasone with other intravitreal corticosteroid implants.

Dexamethasone intravitreal implant has a shorter duration of action than fluocinolone acetonide implant, with macular edema typically reverting to pretreatment levels approximately 5-6 months, and in some cases, as early as 3 months, after injection (Figure 3). Despite the temporary morphological effect, macular edema usually responds to re-treatment. Repeat injections performed at approximately 6-month intervals produce consistent reductions in macular thickness, with no apparent attenuation of response over time (Figure 4).

In comparison to intravitreal anti-VEGF agents, dexamethasone intravitreal implant requires less frequent repeat injection, which might be anticipated to result in fewer injection-related complications, lower treatment costs, and improved patient compliance. Although prospective head-tohead comparisons have yet to be conducted with anti-VEGF agents, dexamethasone intravitreal implant (in common with other injectable corticosteroid implants) is unlikely to replace anti-VEGF agents as first-line therapy for DME because of
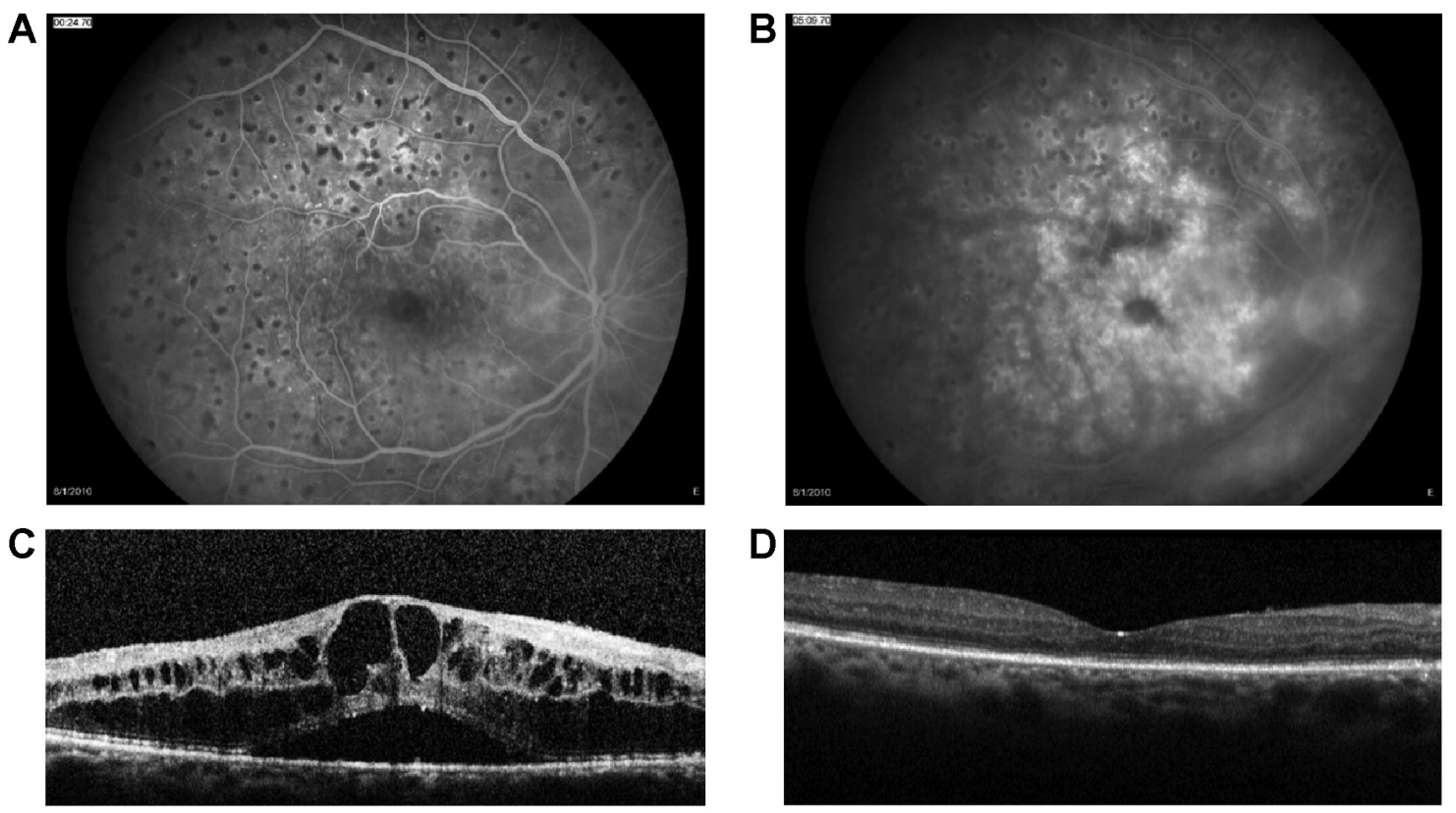

E

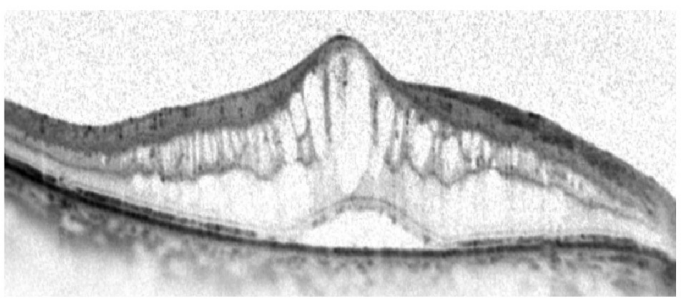

$\mathbf{F}$

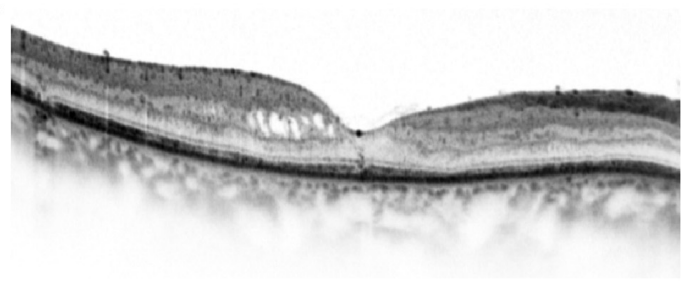

G

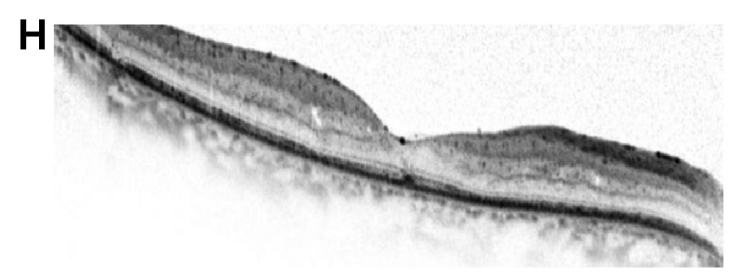

Figure 4 A 65-year-old female with regressed proliferative diabetic retinopathy in the right eye previously treated with three monthly injections of intravitreal bevacizumab. Notes: Early- and late-phase fluorescein angiograms reveal significant leakage, with accumulation in a cystoid pattern, and multiple-scatter scars (A and B). Optical coherence tomography images indicate a decrease in central macular thickness from a baseline (post-bevacizumab) level of $846 \mu \mathrm{m}$ (BCVA 6/30) (C) to a trough of 209 $\mu \mathrm{m}$ (BCVA 6/I5) at II weeks after the first dexamethasone implant injection (D), with reversal of effect occurring by week 20 (CMT 752 $\mu$ m; BCVA 6/I5) (E). Consistent, marked reductions in central macular thickness to trough levels of $222 \mu \mathrm{m}$ (BCVA 6/I2), $209 \mu \mathrm{m}$ (BCVA 6/30), and $235 \mu \mathrm{m}$ (BCVA 6/I5) were recorded 9-12 weeks after the second, third, and fourth dexamethasone implant injections, respectively $(\mathbf{F}-\mathbf{H})$. Images courtesy of $\operatorname{Dr} A$ Loewenstein.

Abbreviation: BCVA, best-corrected visual acuity. 
the risk of steroid-related intraocular complications (notably cataract, IOP elevation, and glaucoma). However, because of its favorable pharmacokinetic properties, dexamethasone intravitreal implant may potentially be an appropriate firstline therapy for DME with foveal involvement in vitrectomized eyes. In addition, it appears to be a suitable treatment option for persistent DME and DME that is unresponsive to anti-VEGF or laser therapy.

Use of dexamethasone intravitreal implant is contraindicated in the following cases: patients with active or suspected ocular or periocular infections, including most viral diseases of the cornea and conjunctiva (eg, dendritic keratitis, vaccinia, and varicella), mycobacterial infections, and fungal diseases; glaucoma patients with a cup-to-disk ratio $>0.8$; patients with a torn or ruptured posterior lens capsule; and patients with known hypersensitivity to any component of the implant. ${ }^{91}$ In addition, use of dexamethasone intravitreal implant (in common with other corticosteroids) is not recommended in patients with a history of ocular herpes simplex because of the risk of viral reactivation. ${ }^{91}$ Similarly, it should be borne in mind that the use of dexamethasone intravitreal implant may increase the risk of secondary ocular infections.

Further insight into the role of dexamethasone intravitreal implant in the treatment of DME, and its optimal schedule of administration, is expected from ongoing/planned clinical trials that are variously exploring its adjunctive use with antiVEGF agents (ClinicalTrials.gov identifier: NCT01309451), in the post-vitrectomy setting (ClinicalTrials.gov identifiers: NCT01788475 and NCT01613716), and in antiVEGF-refractory disease (ClinicalTrials.gov identifiers: NCT01571232, NCT01790685, and NCT 01951066), as well as the effects of a shortened (5-month) re-treatment interval in DME (NCT01492400).

\section{Acknowledgments}

Writing and editorial assistance in preparation of this manuscript was provided to the authors by Andrew Fitton, $\mathrm{PhD}$, of Evidence Scientific Solutions, and was funded by Allergan, Inc.

\section{Disclosure}

PUD reports the following: consultancy fees and research grants - Allergan. FB reports the following: consultancy fees/honoraria and lecture/speakers' bureaux fees - Allergan, Novartis, Farmilia-Thea, Bayer, Pfizer, Alcon, Bausch and Lomb, Genentech, Alimera Sciences, Sanofi-Aventis, ThromboGenics, Hoffmann-La Roche, and Novagali Pharma.
AL reports the following: consultancy fees - Allergan, Alcon, Bayer, Notal Vision, Novartis, and Teva.

\section{References}

1. Klein R, Klein BE, Moss SE, Davis MD, DeMets DL. The Wisconsin epidemiologic study of diabetic retinopathy. IV. Diabetic macular edema. Ophthalmology. 1984;91(12):1464-1474.

2. Antcliff RJ, Marshall J. The pathogenesis of edema in diabetic maculopathy. Semin Ophthalmol. 1999;14(4):223-232.

3. Bhagat N, Grigorian RA, Tutela A, Zarbin MA. Diabetic macular edema: pathogenesis and treatment. Surv Ophthalmol. 2009;54(1):1-32.

4. Yau JW, Rogers SL, Kawasaki R, et al; Meta-Analysis for Eye Disease (META-EYE) Study Group. Global prevalence and major risk factors of diabetic retinopathy. Diabetes Care. 2012;35(3):556-564.

5. Ford JA, Lois N, Royle P, Clar C, Shyangdan D, Waugh N. Current treatments in diabetic macular oedema: systematic review and metaanalysis. BMJ Open. 2013;3(3):e002269.

6. Zhang W, Liu H, Al-Shabrawey M, Caldwell RW, Caldwell RB. Inflammation and diabetic retinal microvascular complications. J Cardiovasc Dis Res. 2011;2(2):96-103.

7. Ehrlich R, Harris A, Ciulla TA, Kheradiya N, Winston DM, Wirostko B. Diabetic macular oedema: physical, physiological and molecular factors contribute to this pathological process. Acta Ophthalmol. 2010; 88(3):279-291.

8. The Diabetes Control and Complications Trial Research Group. The effect of intensive treatment of diabetes on the development and progression of long-term complications in insulin-dependent diabetes mellitus. N Engl J Med. 1993;329(14):977-986.

9. UK Prospective Diabetes Study (UKPDS) Group. Intensive bloodglucose control with sulphonylureas or insulin compared with conventional treatment and risk of complications in patients with type 2 diabetes (UKPDS 33). Lancet. 1998;352(9131):837-853.

10. Antonetti DA, Barber AJ, Bronson SK, et al; JDRF Diabetic Retinopathy Center Group. Diabetic retinopathy: seeing beyond glucose-induced microvascular disease. Diabetes. 2006;55(9):2401-2411.

11. Scholl S, Augustin A, Loewenstein A, Rizzo S, Kupperman B. General pathophysiology of macular edema. Eur JOphthalmol. 2011;21(suppl 6): S10-S19.

12. Stewart MW. Corticosteroid use for diabetic macular edema: old fad or new trend? Curr Diab Rep. 2012;12(4):364-375.

13. Zhang W, Liu H, Rojas M, Caldwell RW, Caldwell RB. Antiinflammatory therapy for diabetic retinopathy. Immunotherapy. 2011; 3(5):609-628.

14. Funatsu H, Noma H, Mimura T, Eguchi S, Hori S. Association of vitreous inflammatory factors with diabetic macular edema. Ophthalmology. 2009;116(1):73-79.

15. Yoshimura T, Sonoda KH, Sugahara M, et al. Comprehensive analysis of inflammatory immune mediators in vitreoretinal diseases. PLoS One. 2009;4(12):e8158.

16. El-Asrar AM, Nawaz MI, Kangave D, et al. High-mobility group box-1 and biomarkers of inflammation in the vitreous from patients with proliferative diabetic retinopathy. Mol Vis. 2011;17:1829-1838.

17. Adamiec-Mroczek J, Oficjalska-Mlyńczak J, Misiuk-Hojło M. Roles of endothelin-1 and selected proinflammatory cytokines in the pathogenesis of proliferative diabetic retinopathy: analysis of vitreous samples. Cytokine. 2010;49(3):269-274.

18. Maier R, Weger M, Haller-Schober EM, et al. Multiplex bead analysis of vitreous and serum concentrations of inflammatory and proangiogenic factors in diabetic patients. Mol Vis. 2008;14:637-643.

19. Lee WJ, Kang MH, Seong M, Cho HY. Comparison of aqueous concentrations of angiogenic and inflammatory cytokines in diabetic macular oedema and macular oedema due to branch retinal vein occlusion. Br J Ophthalmol. 2012;96(11):1426-1430.

20. Miyamoto K, Ogura Y. Pathogenetic potential of leukocytes in diabetic retinopathy. Semin Ophthalmol. 1999;14(4):233-239. 
21. Gardner TW, Antonetti DA, Barber AJ, LaNoue KF, Levison SW. Diabetic retinopathy: more than meets the eye. Surv Ophthalmol. 2002; 47(suppl 2):S253-S262.

22. Joussen AM, Poulaki V, Le ML, et al. A central role for inflammation in the pathogenesis of diabetic retinopathy. FASEB J. 2004; 18(12):1450-1452.

23. Tang J, Kern TS. Inflammation in diabetic retinopathy. Prog Retin Eye Res. 2011;30(5):343-358.

24. Brucklacher RM, Patel KM, VanGuilder HD, et al. Whole genome assessment of the retinal response to diabetes reveals a progressive neurovascular inflammatory response. BMC Med Genomics. 2008;1:26.

25. Joussen AM, Poulaki V, Mitsiades N, et al. Suppression of Fas-FasLinduced endothelial cell apoptosis prevents diabetic blood-retinal barrier breakdown in a model of streptozotocin-induced diabetes. FASEB J. 2003;17(1):76-78.

26. Rojas M, Zhang W, Xu Z, et al. Requirement of NOX2 expression in both retina and bone marrow for diabetes-induced retinal vascular injury. PLoS One. 2013;8(12):e84357.

27. Deissler HL, Deissler H, Lang GK, Lang GE. VEGF but not PlGF disturbs the barrier of retinal endothelial cells. Exp Eye Res. 2013;115: $162-171$.

28. Aveleira CA, Lin CM, Abcouwer SF, Ambrosio AF, Antonetti DA. TNF-alpha signals through PKCzeta/NF-kappaB to alter the tight junction complex and increase retinal endothelial cell permeability. Diabetes. 2010;59(11):2872-2882.

29. Leal EC, Manivannan A, Hosoya K, et al. Inducible nitric oxide synthase isoform is a key mediator of leukostasis and blood-retinal barrier breakdown in diabetic retinopathy. Invest Ophthalmol Vis Sci. 2007;48(11):5257-5265.

30. Antonetti DA, Lieth E, Barber AJ, Gardner TW. Molecular mechanisms of vascular permeability in diabetic retinopathy. Semin Ophthalmol. 1999;14(4):240-248.

31. Barber AJ, Antonetti DA. Mapping the blood vessels with paracellular permeability in the retinas of diabetic rats. Invest Ophthalmol Vis Sci. 2003;44(12):5410-5416.

32. Bolton SJ, Anthony DC, Perry VH. Loss of the tight junction proteins occludin and zonula occludens-1 from cerebral vascular endothelium during neutrophil-induced blood-brain barrier breakdown in vivo. Neuroscience. 1998;86(4):1245-1257.

33. Rangasamy S, McGuire PG, Das A. Diabetic retinopathy and inflammation: novel therapeutic targets. Middle East Afr J Ophthalmol. 2012; 19(1):52-59.

34. Edelman JL. Differentiating intraocular glucocorticoids. Ophthalmologica. 2010;224(suppl 1):25-30.

35. Clark AR, Belvisi MG. Maps and legends: the quest for dissociated ligands of the glucocorticoid receptor. Pharmacol Ther. 2012; 134(1):54-67.

36. Busillo JM, Cidlowski JA. The five Rs of glucocorticoid action during inflammation: ready, reinforce, repress, resolve, and restore. Trends Endocrinol Metab. 2013;24(3):109-119.

37. Solito E, Mulla A, Morris JF, Christian HC, Flower RJ, Buckingham JC. Dexamethasone induces rapid serine-phosphorylation and membrane translocation of annexin 1 in a human folliculostellate cell line via a novel nongenomic mechanism involving the glucocorticoid receptor, protein kinase $\mathrm{C}$, phosphatidylinositol 3-kinase, and mitogen-activated protein kinase. Endocrinology. 2003;144(4):1164-1174.

38. Dalli J, Norling LV, Renshaw D, Cooper D, Leung KY, Perretti M. Annexin 1 mediates the rapid anti-inflammatory effects of neutrophilderived microparticles. Blood. 2008;112(6):2512-2519.

39. Logie JJ, Ali S, Marshall KM, Heck MM, Walker BR, Hadoke PW. Glucocorticoid-mediated inhibition of angiogenic changes in human endothelial cells is not caused by reductions in cell proliferation or migration. PLoS One. 2010;5(12):e14476.

40. Gong Y, Jin X, Wang QS, et al. The involvement of high mobility group 1 cytokine and phospholipases A2 in diabetic retinopathy. Lipid Health Dis. 2014;13:156.
41. Lupo G, Motta C, Giurdanella G, et al. Role of phospholipases A2 in diabetic retinopathy: in vitro and in vivo studies. Biochem Pharmacol. 2013;86(11):1603-1613.

42. Pannicke T, Iandiev I, Wurm A, et al. Diabetes alters osmotic swelling characteristics and membrane conductance of glial cells in rat retina. Diabetes. 2006;55(3):633-639.

43. Tamura H, Miyamoto K, Kiryu J, et al. Intravitreal injection of corticosteroid attenuates leukostasis and vascular leakage in experimental diabetic retina. Invest Ophthalmol Vis Sci. 2005;46(4):1440-1444.

44. Miura Y, Roider J. Triamcinolone acetonide prevents oxidative stressinduced tight junction disruption of retinal pigment epithelial cells. Graefes Arch Clin Exp Ophthalmol. 2009;247(5):641-649.

45. Reichenbach A, Wurm A, Pannicke T, Iandiev I, Wiedemann P, Bringmann A. Muller cells as players in retinal degeneration and edema. Graefes Arch Clinical Exp Ophthalmol. 2007;245(5):627-636.

46. Zhao M, Bousquet E, Valamanesh F, et al. Differential regulations of AQP4 and Kir4.1 by triamcinolone acetonide and dexamethasone in the healthy and inflamed retina. Invest Ophthalmol Vis Sci. 2011;52(9):6340-6347.

47. Hughes PM, Olejnik O, Chang-Lin JE, Wilson CG. Topical and systemic drug delivery to the posterior segments. Adv Drug Deliv Rev. 2005;57(14):2010-2032.

48. Edelhauser HF, Rowe-Rendleman CL, Robinson MR, et al. Ophthalmic drug delivery systems for the treatment of retinal diseases: basic research to clinical applications. Invest Ophthalmol Vis Sci. 2010;51(11):5403-5420.

49. Maurice DM. Drug delivery to the posterior segment from drops. Surv Ophthalmol. 2002;47(suppl 1):S41-S52.

50. Kim SH, Lutz RJ, Wang NS, Robinson MR. Transport barriers in transscleral drug delivery for retinal diseases. Ophthalmic Res. 2007;39(5):244-254.

51. Jager RD, Aiello LP, Patel SC, Cunningham ET Jr. Risks of intravitreous injection: a comprehensive review. Retina. 2004;24(5):676-698.

52. Kwak HW, D'Amico DJ. Evaluation of the retinal toxicity and pharmacokinetics of dexamethasone after intravitreal injection. Arch Ophthalmol. 1992;110(2):259-266.

53. Kaur IP, Kakkar S. Nanotherapy for posterior eye diseases. J Control Release. 2014;193:100-112.

54. Yasukawa T, Ogura Y, Tabata Y, Kimura H, Wiedemann P, Honda Y. Drug delivery systems for vitreoretinal diseases. Prog Retin Eye Res. 2004;23(3):253-281.

55. Moisseiev E, Regenbogen M, Rabinovitch T, Barak A, Loewenstein A, Goldstein M. Evaluation of pain during intravitreal Ozurdex injections vs intravitreal bevacizumab injections. Eye. 2014;28(8):980-985.

56. Meyer CH, Klein A, Alten F, et al. Release and velocity of micronized dexamethasone implants with an intravitreal drug delivery system: kinematic analysis with a high-speed camera. Retina. 2012;32(10):2133-2140.

57. Berarducci A, Sian IS, Ling R. Inadvertent dexamethasone implant injection into the lens body management. Eur J Ophthalmol. 2014; 24(4):620-622.

58. Coca-Robinot J, Casco-Silva B, Armada-Maresca F, Garcia-Martinez J. Accidental injections of dexamethasone intravitreal implant (Ozurdex) into the crystalline lens. Eur J Ophthalmol. 2014;24(4):633-636.

59. Fasce F, Battaglia Parodi M, Knutsson KA, et al. Accidental injection of dexamethasone intravitreal implant in the crystalline lens. Acta Ophthalmol. 2014;92(4):e330-e331.

60. Agrawal R, Fernandez-Sanz G, Bala S, Addison PK. Desegmentation of Ozurdex implant in vitreous cavity: report of two cases. $\mathrm{Br} \mathrm{J} O \mathrm{ph}$ thalmol. 2014;98(7):961-963.

61. Donmez O, Parlak M, Yaman A, Saatci AO. Splitting of a dexamethasone implant (Ozurdex) following the injection. Case Rep Ophthalmol Med. 2013;2013:247949.

62. Roy R, Hegde S. Split Ozurdex implant: a caution. Can J Ophthalmol. 2013;48(1):e15-e16.

63. Rishi P, Mathur G, Rishi E. Fractured Ozurdex ${ }^{\mathrm{TM}}$ implant in the vitreous cavity. Ind J Ophthalmol. 2012;60(4):337-338. 
64. Wai Ch'ng S, Padroni S, Banerjee S. Anterior vitreous displacement of the intravitreal dexamethasone implant (Ozurdex). Eye. 2014;28(2):238-239.

65. Khurana RN, Appa SN, McCannel CA, et al. Dexamethasone implant anterior chamber migration: risk factors, complications, and management strategies. Ophthalmology. 2014;121(1):67-71.

66. Kishore SA, Schaal S. Management of anterior chamber dislocation of dexamethasone implant. Ocul Immunol Inflamm. 2013;21(1):90-91.

67. Vela JI, Crespi J, Andreu D. Repositioning of dexamethasone intravitreal implant (Ozurdex) migrated into the anterior chamber. Intl Ophthalmol. 2012;32(6):583-584.

68. Bansal R, Bansal P, Kulkarni P, Gupta V, Sharma A, Gupta A. Wandering Ozurdex $\left({ }^{\circledR}\right)$ implant. J Ophthalmic Inflamm Infect. 2012;2(1):1-5.

69. Malclès A, Janin-Manificat H, Yhuel Y, et al. [Anterior chamber migration of intravitreal dexamethasone implant $\left(\mathrm{Ozurdex}^{\circledR}\right)$ in pseudophakic eyes: report of three cases]. J Franc Ophtalmol. 2013;36(4):362-367. French.

70. Chang-Lin JE, Attar M, Acheampong AA, et al. Pharmacokinetics and pharmacodynamics of a sustained-release dexamethasone intravitreal implant. Invest Ophthalmol Vis Sci. 2011;52(1):80-86.

71. Chang-Lin JE, Burke JA, Peng Q, et al. Pharmacokinetics of a sustainedrelease dexamethasone intravitreal implant in vitrectomized and nonvitrectomized eyes. Invest Ophthalmol Vis Sci. 2011;52(7):4605-4609.

72. Weijtens O, Feron EJ, Schoemaker RC, et al. High concentration of dexamethasone in aqueous and vitreous after subconjunctival injection. Am J Ophthalmol. 1999;128(2):192-197.

73. Weijtens O, van der Sluijs FA, Schoemaker RC, et al. Peribulbar corticosteroid injection: vitreal and serum concentrations after dexamethasone disodium phosphate injection. Am J Ophthalmol. 1997;123(3):358-363.

74. Weijtens O, Schoemaker RC, Romijn FP, Cohen AF, Lentjes EG, van Meurs JC. Intraocular penetration and systemic absorption after topical application of dexamethasone disodium phosphate. Ophthalmology. 2002;109(10):1887-1891.

75. Weijtens O, Schoemaker RC, Cohen AF, et al. Dexamethasone concentration in vitreous and serum after oral administration. Am JOphthalmol. 1998;125(5):673-679.

76. Chin HS, Park TS, Moon YS, Oh JH. Difference in clearance of intravitreal triamcinolone acetonide between vitrectomized and nonvitrectomized eyes. Retina. 2005;25(5):556-560.

77. Haller JA, Kuppermann BD, Blumenkranz MS, et al; Dexamethasone DDS Phase II Study Group. Randomized controlled trial of an intravitreous dexamethasone drug delivery system in patients with diabetic macular edema. Arch Ophthalmol. 2010;128(3):289-296.

78. Kuppermann BD, Chou C, Weinberg DV, Whitcup SM, Haller JA, Blumenkranz MS. Intravitreous dexamethasone effects on different patterns of diabetic macular edema. Arch Ophthalmol. 2010; 128(5):642-643

79. Beer PM, Bakri SJ, Singh RJ, Liu W, Peters GB 3rd, Miller M. Intraocular concentration and pharmacokinetics of triamcinolone acetonide after a single intravitreal injection. Ophthalmology. 2003;110(4):681-686.
80. Boyer DS, Faber D, Gupta S, et al; Ozurdex CHAMPLAIN Study Group. Dexamethasone intravitreal implant for treatment of diabetic macular edema in vitrectomized patients. Retina. 2011;31(5):915-923.

81. Callanan DG, Gupta S, Boyer DS, et al; Ozurdex PLACID Study Group. Dexamethasone intravitreal implant in combination with laser photocoagulation for the treatment of diffuse diabetic macular edema. Ophthalmology. 2013;120(9):1843-1851.

82. Boyer DS, Yoon YH, Belfort R Jr, et al. Three-year, randomized, shamcontrolled trial of dexamethasone intravitreal implant in patients with diabetic macular edema. Ophthalmology. 2014;121(10):1904-1914.

83. Danis RP, Sadda S, Cui H, Li X-Y, Hashad Y, Whitcup SM. Anatomic outcomes with dexamethasone intravitreal implant in diabetic macular edema: a pooled analysis of two randomized Phase III trials. ARVO 2014 Annual Meeting; May 4-8, 2014, Orlando, FL.

84. Sadda S, Danis RP, Li X-Y, Cui H, Hashad Y, Whitcup SM. Anatomic effects of dexamethasone intravitreal implant in diabetic macular edema: pooled analysis of findings from two randomized Phase 3 studies. 32nd Annual Meeting of the American Society of Retina Specialists; August 9-13, 2014; San Diego.

85. Lazic R, Lukic M, Boras I, et al. Treatment of anti-vascular endothelial growth factor-resistant diabetic macular edema with dexamethasone intravitreal implant. Retina. 2014;34(4):719-724.

86. Sorkin N, Loewenstein A, Habot-Wilner Z, Goldstein M. Intravitreal dexamethasone implant in patients with persistent macular edema of variable etiologies. Ophthalmologica. 2014;232(2):83-91.

87. Dutra Medeiros M, Postorino M, Navarro R, Garcia-Arumi J, Mateo C, Corcostegui B. Dexamethasone intravitreal implant for treatment of patients with persistent diabetic macular edema. Ophthalmologica. 2014;231(3):141-146

88. Pacella E, Vestri AR, Muscella R, et al. Preliminary results of an intravitreal dexamethasone implant $\left(\right.$ Ozurdex $\left.{ }^{\circledR}\right)$ in patients with persistent diabetic macular edema. Clin Ophthalmol. 2013;7:1423-1428.

89. Zucchiatti I, Lattanzio R, Querques G, et al. Intravitreal dexamethasone implant in patients with persistent diabetic macular edema. Ophthalmologica. 2012;228(2):117-122.

90. Thakur A, Kadam R, Kompella UB. Trabecular meshwork and lens partitioning of corticosteroids: implications for elevated intraocular pressure and cataracts. Arch Ophthalmol. 2011;129(7):914-920.

91. Anon. Ozurdex Prescribing Information; 2014. Available from: http:// www.allergan.com/assets/pdf/ozurdex_pi.pdf. Accessed March 27, 2015.

92. Campochiaro PA, Brown DM, Pearson A, et al; FAME Study Group. Sustained delivery fluocinolone acetonide vitreous inserts provide benefit for at least 3 years in patients with diabetic macular edema. Ophthalmology. 2012;119(10):2125-2132.
Clinical Ophthalmology

\section{Publish your work in this journal}

Clinical Ophthalmology is an international, peer-reviewed journal covering all subspecialties within ophthalmology. Key topics include: Optometry; Visual science; Pharmacology and drug therapy in eye diseases; Basic Sciences; Primary and Secondary eye care; Patient Safety and Quality of Care Improvements. This journal is indexed on Submit your manuscript here: http://www.dovepress.com/clinical-ophthalmology-journa

\section{Dovepress}

PubMed Central and CAS, and is the official journal of The Society of Clinical Ophthalmology (SCO). The manuscript management system is completely online and includes a very quick and fair peer-review system, which is all easy to use. Visit http://www.dovepress.com/ testimonials.php to read real quotes from published authors. 